\title{
Commentary: Hybrid thoracoabdominal aortic aneurysm repair: One step closer with the SPIDER graft
}

\author{
Lars Stangenberg, $\mathrm{MD}, \mathrm{PhD},{ }^{\mathrm{a}}$ and Neel R. Sodha, $\mathrm{MD}^{\mathrm{b}}$
}

\footnotetext{
From the Divisions of ${ }^{\mathrm{a}}$ Vascular \& Endovascular Surgery and ${ }^{\mathrm{b}}$ Cardiothoracic Surgery, Department of Surgery, Alpert Medical School, Brown University, Providence, RI.

Disclosures: Authors have nothing to disclose with regard to commercial support.

Received for publication Nov 26, 2018; accepted for publication Nov 28, 2018; available ahead of print Feb 10, 2019.

Address for reprints: Neel R. Sodha, MD, Lifespan Thoracic Aortic Center, Alpert Medical School, Brown University, 2 Dudley St, MOC 360, Providence, RI 02905 (E-mail: nsodha@ lifespan.org).

J Thorac Cardiovasc Surg 2019;158:704-5

$0022-5223 / \$ 36.00$

Copyright $₫ 2018$ Published by Elsevier Inc. on behalf of The American Association for Thoracic Surgery https://doi.org/10.1016/j.jtcvs.2018.11.112
}

Wipper and colleagues ${ }^{1}$ are to be congratulated on the excellent results of the present study. Building on their previous work, they show the feasibility of an updated SPIDER graft in the repair of thoracoabdominal aortic aneurysms in a porcine model and provide data on visceral and spinal perfusion. The graft uses a hybrid approach and combines an endovascular stent graft for proximal seal with a classic branched polyester graft for distal anastomosis and revascularization of the visceral branches. This is accomplished by open retroperitoneal exposure without the need for a thoracotomy. This could significantly reduce pulmonary complications in the clinical setting, which are a major driver of morbidity and mortality. ${ }^{2}$ Furthermore, through an elegant sequence of the various anastomoses and stent graft deployment, they demonstrate sufficient perfusion to organs and the spine, to likely avoid complications without the need for cardiopulmonary bypass. Intriguingly, the spinal perfusion in one of the SPIDER graft groups even seems to improve over baseline flow.

There are some caveats that merit further discussion. This is a preclinical study in a porcine model with normal aortic anatomy and size. Although demonstrating excellent technical feasibility, graft durability remains unknown. A primary aim of the study evaluated spinal cord perfusion, but as the authors have noted, the porcine spinal blood supply is markedly different than in humans, with pigs having much smaller thoracic and lumbar arteries, often originating as a single branch from the aorta, thus potentially limiting the conclusions that can be drawn. ${ }^{3}$ In addition, the control group undergoing open repair did not undergo spinal drainage or reimplantation of portions of the segmental blood supply to the spine, both of which can impact spinal perfusion. From a technical point of view, the intraoperative management of the intercostal arteries that arise from the aneurysmal thoracic aorta will be particularly challenging, as there will be significant back bleeding, thereby creating a siphon effect and potentially causing spinal cord ischemia, until the Siena collar is sewn in place. Furthermore, crucial vascular surgeon. ward that goal.

\section{References}

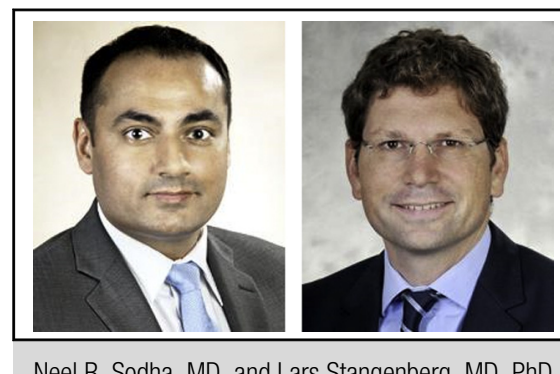

Neel R. Sodha, MD, and Lars Stangenberg, MD, PhD

Central Message

The evolving SPIDER graft represents a significant technical advance in the management of complex thoracoabdominal aortic disease. The current preclinical study in a porcine model demonstrates the ability to maintain reasonable visceral and spinal cord perfusion and avoid the need for a thoracotomy and cardiopulmonary bypass. Although preclinical studies in swine are encouraging, additional technical challenges translating this success to patients will need to overcome obstacles, including management of intercostal arteries, and demonstrate long-term durability.

See Article page 692.

intercostal arteries in the distal descending thoracic aorta cannot be reimplanted. Finally, one wonders where this graft technology will fit in the armamentarium of the cardio-

Open repair, after decades of refinement of technique and perioperative management, yields good results for this complex disease in specialized, high-volume centers. Full endovascular repair using branched and fenestrated graft technology has been available in specialized centers for more than a decade and has similar long-term results, including patency of visceral vessels exceeding $90 \%{ }^{4}$ Will the SPIDER graft technology combine the best of these 2 worlds and significantly improve on patient outcomes, as seen recently with the hybrid approach to carotid artery revascularization, ${ }^{5}$ or will it combine the shortcomings of both techniques? This question remains to be answered, but the present study demonstrates excellent progress to-

1. Wipper S, Kölbel T, Sandhu HK, Manzoni D, Duprée A, Estrera AL, et al. Impact of hybrid thoracoabdominal aortic repair on visceral and spinal cord 
perfusion: the new and improved SPIDER-graft. J Thorac Cardiovasc Surg. 2019; 158:692-701.

2. Etz CD, Di Luozzo G, Bello R, Luehr M, Khan MZ, Bodian CA, et al. Pulmonary complications after descending thoracic and thoracoabdominal aortic aneurysm repair: predictors, prevention, and treatment. Ann Thorac Surg. 2007;83:S870-6.

3. Strauch JT, Lauten A, Zhang N, Wahlers T, Griepp RB. Anatomy of the spinal cord blood supply in the pig. Ann Thorac Surg. 2007;83:2130-4.
4. Oderich GS, Ribeiro M, Reis de Souza L, Hofer J, Wigham J, Cha S. Endovascular repair of thoracoabdominal aortic aneurysms using fenestrated and branched endografts. J Thorac Cardiovasc Surg. 2017;153:S32-41.

5. Malas MB, Dakour-Aridi H, Wang GJ, Kashyap VS, Motaganahalli RL, Eldrup-Jorgensen J, et al. Transcarotid artery revascularization versus transfemoral carotid artery stenting in the Society for Vascular Surgery Vascular Quality Initiative. J Vasc Surg. 2019;69:92-103.e2. 